\title{
A VIVÊNCIA DE PAIS E PROFISSIONAIS NA UNIDADE DE TERAPIA INTENSIVA NEONATAL ${ }^{1}$
}

\author{
THE EXPERIENCE BY PARENTS AND PROFESSIONALS \\ AT A NEONATAL INTENSIVE THERAPY UNIT
}

\section{LA VIVENCIA DE PADRES Y PROFESIONALES EN LA UNIDAD DE TERAPIA INTENSIVA NEONATAL}

\author{
ELysângela Dittz Duarte* \\ Roseni Rosângela de SENA ${ }^{* *}$ \\ César Coelho Xavier ${ }^{* * *}$
}

\begin{abstract}
RESUMO
Este estudo teve como objetivo apreender a vivência dos pais e profissionais na Unidade de Terapia Intensiva Neonatal. Os sujeitos foram doze profissionais e oito pais de recém-nascidos. Para coleta dos dados utilizaramse a Oficina de trabalho e a Observação de campo. No tratamento dos dados utilizou-se a Análise de Discurso. Mostrou-se como pais e profissionais vivenciam a internação e como o cotidiano que compartilham os transformam, permitindo-lhes criar outros sentidos para a vida e para o cuidar. Verifica-se que a presença dos pais ressignifica o ambiente assistencial e o cuidado e amplia as demandas de cuidado da criança. Acreditamos na necessidade de intervenções na Unidade de Terapia Intensiva Neonatal a partir do vivenciado por pais e profissionais, utilizando-se os diferentes olhares para a produção de um cuidado integral.
\end{abstract}

Palavras chave: Unidades de terapia intensiva neonatal, assistência integral à saúde, pais.

\begin{abstract}
This study aimed to gather knowledge of the experience of parents and professionals in a Neonatal Intensive Care Unit. The subjects were twelve professional and eight parents of newborns. Data collection was analyzed using Discourse Analysis. It was observed how parents and health professionals co-exits in a hospital setting as well as how their day-to-day life activities devoted to sharing allows them to create a sense to life and caring for one another. The presence of parents re-enforces an environment and care setting which increases the demands of child care. We believe in the need for interventions at Neonatal Intensive Care Unit based on the experience observing parents and professionals, using different manners of observation for the creation of an integral care.
\end{abstract}

Key words: Neonatal intensive care units, comprehensive health care, parents.

\footnotetext{
${ }^{1}$ Texto extraído da tese de doutorado "A integralidade do cuidado ao recém-nascido na Unidade de Terapia Intensiva Neonatal: saberes e práticas dos profissionais".

* Enfermeira, Professora Departamento de Enfermagem Materno Infantil da Escola de Enfermagem da Universidade Federal de Minas Gerais, Doutora em Ciências da Saúde da Criança e do Adolescente pela Faculdade de Medicina da UFMG. Minas Gerais, Brasil. E-mail: dittzduarte@ig.com.br

${ }^{* *}$ Enfermeira, Professora Emérita da Escola de Enfermagem da UFMG, Doutora em Enfermagem pela Escola de Enfermagem da Universidade São Paulo. E-mail: rosenisena@uol.com.br

${ }_{* * *}$ Professor Associado do Departamento de Pediatria da Faculdade de Medicina da UFMG. Doutor em Saúde da Criança e Adolescente pela Universidade de São Paulo. E-mail: xavier@medicina.ufmg.br
} 


\section{RESUMEN}

Este estudio tuvo por objetivo aprehender la vivencia de los padres y profesionales en la Unidad de Terapia Intensiva Neonatal. Los sujetos fueron doce profesionales y ocho padres de recién nacidos. Para la recogida de datos se utilizó el taller de trabajo y la observación de campo. Para el tratamiento de los datos se utilizó el Análisis de Discurso. Quedó en evidencia cómo los padres y profesionales viven el ingreso y cómo el día a día que comparten los transforma, permitiéndoles crear otros sentidos para la vida y para el cuidar. Se comprobó que la presencia de los padres trae otro significado al ambiente asistencial y al cuidado, y amplía las demandas de cuidado del niño. Creemos en la necesidad de intervenciones en la Unidad a partir de lo vivenciado por padres y profesionales, utilizando las diferentes miradas para la producción de un cuidado integral.

Palabras clave: Unidades de terapia intensiva neonatal, atención integral de salud, padres.

Fecha recepción: 19.03.10 Fecha aceptación: 01.08.11

\section{INTRODUÇÃO}

As Unidades de Terapia Intensiva (UTI) são espaços de cuidado diferenciados especialmente pela alta incorporação tecnológica e rigorosa rotina de cuidado com os pacientes frente a suas condições de urgência e de necessidade de manutenção da vida (1). Um cuidado voltado para a doença, por vezes desconsiderando a subjetividade aí existente. Essas são características que colaboram para que as Unidades de Terapia Intensiva Neonatais (UTINs) constituam-se em setores de maior especialização do cuidado aos recémnascidos dentro das instituições de saúde, possibilitando maior sobrevida dos neonatos prematuros e/ou doentes, associado a um maior tempo de permanência nos hospitais. Esse contexto de cuidado neonatal tem colocado pais ${ }^{*}$ e familiares frente a formas de cuidar de seus filhos em espaços de cuidado diferentes daqueles por eles esperados (2).

Com a internação dos neonatos, seus pais passam a conviver com um ambiente com constantes ruídos advindos de monitores, respiradores, incubadoras e bombas de infusão, com forte iluminação e odores químicos (3). Os pais ainda convivem com a frustração de não poder desempenhar tarefas parentais esperadas, como prover alimento e proteção para seus filhos (4-7), e com a ansiedade relacionada à incerteza da sobrevivência da criança (8). Esses fatores, associados à separação precoce da mãe e de seu recém-nascido, são apontados como capazes de alterar o desenvolvimento do vínculo entre mãe e filho $(6,9)$.

Os profissionais, por sua vez, têm o espaço da UTIN como seu ambiente de trabalho no qual fazem uso de vários equipamentos e tecnologias no cuidado a recém-nascidos graves. Estes, por sua instabilidade, exigem constante tomada de decisão que acaba por gerar tensão (10) influenciando na assistência prestada aos recém-nascidos e a relação entre os pais e os profissionais.

Para amenizar o momento de crise enfrentado pelos pais de recém-nascidos em UTIN e propiciar condições que sejam favorecedoras de seu desenvolvimento, tem-se buscado que os pais participem do cuidado a seus filhos durante a internação na UTIN, com a presença física ou a co-participação no cuidado da criança (11). Entretanto, verifica-se que embora os profissionais tenham conhecimento da importância dos pais no cuidado, isso nem sempre acontece no coti- 
diano (12).

Ao serem expostos à situação de terem um filho na UTIN e de participarem do cuidado nesse ambiente assistencial, pais e mães vivenciam de diferentes maneiras esse período, podendo ou não ser favorecedor de um cuidado integral ao recém-nascido e do desenvolvimento da capacidade dos pais de cuidar e vincular-se ao filho.

Partindo desses pressupostos o presente artigo tem como objetivo apreender a vivência de pais e profissionais na UTIN durante a internação do seu filho.

\section{MATERIAL E MÉTODO}

Trata-se de um estudo descritivo, de natureza qualitativa devido às possibilidades dessa abordagem para aproximação do universo de significados, aspirações, atitudes, crenças e valores da população estudada (13).

$O$ estudo considera a dinâmica interação social dos atores, na qual eles se transformam e também se firmam como produtores de novas realidades. Foi pelo reconhecimento desse dinamismo, da provisoriedade, da transformação e da autoria dos profissionais e pais que fizemos opção pela abordagem qualitativa sob a perspectiva da dialética para a compreensão dessa realidade.

Esta modalidade nos permite evidenciar as contradições e desafios que o cotidiano estudado apresenta para a construção de uma atenção integradora ao recém-nascido e sua família, visto que se fundamenta na explicação do movimento e da transformação das coisas (13).

O estudo teve como cenário o Hospital Sofia Feldman (HSF), uma instituição filantrópica, localizada em Belo Horizonte, Minas Gerais, e que atende exclusivamente usuários do Sistema Único de Saúde (SUS). A UTIN desse Hospital foi criada em 2000 e possui 32 leitos, organizados em três unidades assistenciais, com uma média de 58 internações/ mês. Atuam nesse espaço de cuidado técnicas de enfermagem, médicos, enfermeiros, fisioterapeutas, psicólogas, assistentes sociais e terapeutas ocupacionais.

Nessa instituição, como um dos incentivos à permanência das mães, é franqueado o acesso nas 24 horas do dia. Os pais têm o acesso entre 9:00 e 21:00 horas, podendo ser ampliado de acordo com o quadro clínico do RN. Na UTIN podem fazer uso de cadeiras para melhor permanecerem próximo de seu filho.

Outra estratégia institucional que visa favorecer a proximidade da mãe junto a seu filho internado na UTIN é a Casa de Sofias. Trata-se de uma Casa destinada à hospedagem das mães onde recebem apoio constante de uma equipe multiprofissional com suporte psicológico, grupos de vivência, atividades manuais e lúdicas. Verifica-se, ainda, a possibilidade de maior contato entre os pais e seu filho pela adoção do Método Mãe-Canguru na Instituição.

A escolha do HSF para cenário deste estudo deve-se às características da instituição em orientar suas práticas para uma atenção integral à mulher e ao recém-nascido e aos trabalhos aí desenvolvidos pela pesquisadora, onde atuava como enfermeira.

Os sujeitos da pesquisa foram 12 profissionais da equipe de saúde que atuavam na UTIN e 8 pais dos recém-nascidos internados. Para os pais, adotaram-se, como critérios de inclusão, um período de internação dos filhos igual ou superior a sete dias e sua participação no cuidado a seus filhos.

Para este estudo utilizaram-se, como estratégias de coleta de dados, a Observação de Campo e a Oficina de Trabalho (14). As oficinas tiveram como temas norteadores: a assistência ao recém-nascido na UTIN do HSF e a prática dos profissionais na UTIN: os elementos que garantem a integralidade da assistência.

Foram realizadas duas oficinas, sendo uma com os pais (Grupo 1) e outra com os profissionais (Grupo 2). Para os participan- 
tes dos dois grupos, no momento do convite foi explicado acerca do estudo, dado espaço para perguntas e esclarecido as dúvidas. Para o Grupo 1 foram convidados dois pais e oito mães que atendiam aos critérios de inclusão tendo comparecido um pai e sete mães. Para a estruturação do Grupo 2, os nomes dos profissionais que atuavam na UTIN foram inicialmente distribuídos em envelopes identificados pela categoria profissional e, em seguida, feito o sorteio, buscando-se manter, no grupo, a proporção existente na equipe assistencial. Foram incluídos profissionais de todas as categorias, sendo 1 terapeuta ocupacional, 1 assistente social, 1 psicóloga, 1 enfermeira, 4 técnicas de enfermagem, 3 pediatras e 1 fisioterapeuta, constituindo-se um grupo de 12 participantes.

Antes de iniciar a oficina de cada um dos grupos, foram reiteradas as informações sobre os objetivos e critérios adotados na pesquisa e solicitadas a assinatura do Termo de Consentimento Livre e Esclarecido-TCLE.

As oficinas foram gravadas e transcritas pela pesquisadora. Em seguida, fez-se a substituição dos nomes dos participantes. Assim, os usuários receberam nomes de flores seguidos da letra $U$ e os profissionais receberam nomes de pedras preciosas seguidos da letra P. À medida que as unidades de sentido eram extraídas do texto, recebiam também uma numeração (ex.: Ametista P-21). Sempre que apresentados fragmentos das falas dos informantes, utilizaram-se itálico e aspas.

A Observação de Campo ocorreu no período de 18 de agosto a 17 de outubro de 2006, em diferentes dias e horários, com duração de 10 minutos a duas horas com registro no Diário de Campo.

Para a organização do material, foi realizada a sua leitura, feita a identificação das unidades de sentido que foram codificadas de acordo com a sua ordem de extração no texto. Uma vez identificadas as unidades de sentido foram então recortadas e agrupadas de acordo com a sua similaridade emergindo as categorias empíricas.
As observaçoes relatadas no Diário de Campo foram utilizadas para melhor compreensão e contextualização do discurso dos usuários e profissionais e para isso, buscouse relacioná-las às unidades de sentido que compuseram as categorias empíricas.

Utilizou-se a perspectiva da Análise de Discurso para se trabalhar o material produzido considerando-se as possibilidades oferecidas de se refletir sobre as condições nas quais é construída e apreendida a realidade. Nessa perspectiva, a linguagem "não pode apenas representar algo já dado, sendo parte de uma construção social que rompe com a ilusão de naturalidade entre os limites do linguístico e os do extralinguístico. A linguagem não se dissocia da interação social"(15).

O projeto teve a aprovação dos Comitês de Ética em Pesquisa do Hospital Sofia Feldman (Parecer 04/06) e da Universidade Federal de Minas Gerais (Parecer 080/06).

\section{RESULTADOS}

Os dados foram analisados buscando-se apreender a vivência dos pais e profissionais na UTIN. A partir do organização dos discursos obtidos, foi possível a constituição de quatro categorias: a internação na UTIN, dificuldades enfrentadas por pais e profissionais, relação de pais e profissionais e participação da família

\section{A internação na UTIN}

Depreende-se, do discurso dos profissionais participantes da Oficina, como percebem os pais e as mães no período inicial da admissão do bebê. Turfa (P-47) ressalta, desse período, as dúvidas tanto da mãe quanto da família pela incerteza da vida do bebê: "ela tá ali e a gente não sabe se ela vai sobreviver, se ela vai morrer, e tal".

Diamante (P-63) revela as modificações que identifica na mãe cujo filho encontra- 
se internado na UTIN pois a mãe fica "super tranquilinha, conversa com a gente, depois ela começa a ficar estressada, xinga todo mundo". Ela reconhece que essa situação enfrentada pelas mães é difícil e que a equipe "tem que tentar se colocar no lugar dela também".

Orquídea (U-1) evidencia, em seu discurso, que, além de os pais terem sua atenção centrada em seus filhos, as condições clínicas dos bebês interferem diretamente na tranqüilidade tanto de pais quanto de profissionais. A imprevisibilidade dos acontecimentos na UTIN é reforçada por Papoula (U-4).

Turfa (P-54) ressalta as necessidades familiares mediante a situação de internação dos bebês ao expressar a espera por informação, o desconhecimento do ambiente onde os bebês são cuidados e a incerteza da vida ante a doença.

Algumas situações que foram registradas a partir da observação de campo permitiram identificar como tem sido o processo de informação para os pais. Foi evidenciado que, além de ressaltar os aspectos relacionados à patologia, são também valorizados aqueles que reforçam as debilidades da criança.

Para Gardênia (U-40), é importante não permanecer com dúvida. Ela diz estimular as outras mães a perguntar sempre que não compreenderem o que acontece com seus bebês ou desconhecerem algo quanto aos cuidados que estão recebendo. Considera um momento oportuno para isso o contato com o pediatra, na hora da passagem de notícias.

Girassol (U-9 e 11) considera que aprende acompanhando sua filha na Unidade e, desse aprendizado, refere-se principalmente à paciência.

\section{Dificuldades enfrentadas por pais e profissionais}

O discurso de Gardênia (U-16 e 18) é revelador dos obstáculos que os pais enfrentam na Unidade. Afirma que, durante esse período em que está aqui, aprendeu a não desistir diante das dificuldades mas a buscar supe- rá-las porque "a gente acha que não vai dar conta... que não vai superar... e que no final a gente sempre tem uma recompensa, por mais que chegue cansada do outro lado".

Os discursos dos profissionais participantes da Oficina permitem evidenciar suas limitações para lidar com os resultados indesejáveis da assistência prestada aos neonatos, como a ocorrência de sequelas e óbitos. Ágata (P-26) fala que é uma "carga muito pesada" lidar com uma criança sequelada, que a sequela ocorre frequentemente e não dá para os profissionais ficarem se culpando por isso.

A dificuldade de lidar com o óbito é apresentada por Ametista (P-23), ao relatar que buscou ajuda com a psicóloga para dar a notícia de que um recém-nascido havia falecido. Ametista relata que pediu à psicóloga que a acompanhasse na notícia que daria à mãe sobre o óbito de seu filho, pois não sabia como fazê-lo e a psicóloga respondeu-lhe: “(...) Você vai fazer dez vezes e dez vezes você vai ter a sensação de que não está fazendo o melhor. $O$ menino morreu, então é difícil mesmo".

O impacto do óbito sobre a equipe é percebido pelos pais ao identificarem o sentimento de tristeza nos profissionais, o que é evidenciado pela descrição de Orquídea (U-25) de como a pediatra estava após um falecimento: "no outro dia de manhã ela saiu toda mudada, parecia que nem era ela de tão... tão acabada mesmo. Porque morreu no plantão dela".

\section{Relação de pais e profissionais}

Mesmo sendo reconhecida pelos profissionais, como no relato de Diamante (P-63), a necessidade de se compreenderem as mudanças sofridas pelas mães durante a internação, o discurso das usuárias revela uma relação entre as mães e os profissionais estriada por atitudes ríspidas e pouco receptivas. Situações como as apresentadas por Orquídea (U-66), ao falar de duas profissionais (técnicas de enfermagem) que, mesmo sabendo 
a difícil situação em que elas [mães] se encontram e o quanto "uma palavra que uma pessoa fala com a gente [as mães], a gente pode sentir muito, elas [técnicas de enfermagem] não lhe respondem direito". Orquídea (U-68) acrescenta que tem algumas [técnicas de enfermagem] que "fecham a cara quando vê que a gente tá chegando, fica mal humorada, e fica falando: Nossa! Se eu pudesse eu estudava prá mim poder sair daqui!".

Os comportamentos evidenciados nos relatos de Orquídea (U-66, 68) recebem o matiz do poder que se revela no diálogo com um profissional no qual ela lhe diz que sua "menina não gosta de ficar deitada de barriga pra baixo" e recebe como resposta que a criança "não tem que gostar não, ela tem que ficar é assim".

\section{Participação da família}

Depreende-se, do discurso dos informantes, o valor que conferem à participação da família no cuidado ao recém-nascido e quem de fato a compõe. Os discursos revelam os entendimentos que os pais e os profissionais têm dessa participação e o que fazem para efetivá-la, apontando as possibilidades e os limites de atuação.

Turfa (P-43) expressa a presença materna junto ao filho durante a internação como algo bem solidificado na instituição o que, segundo ela, é garantido pelas estratégias empregadas que dão condições a essas mulheres de permanecer ao lado de seus recém-nascidos. Para Ametista (P-21) "por mais que falha em dar notícia, falha em dar assistência, em pouquíssimos lugares você vê isso [...] porque eu acho que a família, aqui ela é valorizada mais do que em outros lugares".

Na perspectiva de participação da família, Turfa (P-51) afirma que se fala muito de família, "mas o tempo todo a gente tá falando da mãe, da mãe, da mãe”. Para a informante, isso se constata em momentos como o acolhimento e a oferta da Casa de Sofias para a permanência das mães. Segundo Turfa (P-
51), os acolhimentos são feitos sem que se chamem os pais ou os avós para participar.

Turfa (P-44) expressa as dificuldades vivenciadas pelas mães durante a internação, como os conflitos com "a vida pessoal, as dimensões da vida em ser mãe" e as cobranças que a equipe faz a essa mulher a partir do que identifica que ela pode oferecer: o leite e a presença 24 horas. Para Turfa (P-45), o fato de a mãe ter uma infra-estrutura que lhe dá condições favoráveis para permanecer faz com que a equipe faça juízo de valor negativo sobre as mães que não ficam na instituição o tempo todo, "muitas vezes aquela mãe não é uma mãe boa porque ela não está dormindo aqui”.

\section{DISCUSSÃO}

Os dados apresentados emergiram do desejo dos informantes de falarem da Unidade assistencial expressando a densidade das relações e sentimentos vivenciados nesse locus de produção de cuidado e suas implicações no cotidiano assistencial.

As possibilidades de melhora ou de piora súbita dos recém-nascidos fazem parte do cotidiano dos pais que os acompanham trazendo incerteza durante a internação. Essa incerteza diz respeito à possibilidade de seus filhos melhorarem significativamente, ficarem em um estado de enfermidade crônica ou até mesmo morrerem (16).

As mudanças ocorridas na mulher, durante a internação de seu filho, sinalizam para a necessidade de um cuidado direcionado às mães, permitindo inferir que as ações não devem limitar-se ao recém-nascido. A presença das mães reconfigura as necessidades de saúde do recém-nascido e delas próprias e traz, para dentro da UTIN, a necessidade de se estabelecerem novas relações das mães com a equipe para uma construção conjunta das condições que poderão favorecer o cuidado a essas crianças. 
Outro aspecto revelado pelos dados diz respeito à necessidade que mães e pais têm de buscar informações para esclarecer suas dúvidas sobre seus filhos. Estudos apontam a busca dos pais por informação e sua importância para a redução do estresse causado pela internação de seus filhos e para compreender o que se passa com eles (1721). Mesmo se sabendo da importância da informação, sua oferta é insuficiente (22). Verificamos, em nosso estudo, que a informação ainda ocorre no tempo e no assunto de escolha dos profissionais e ressalta os aspectos de evolução da doença e a terapêutica utilizada.

Os dados possibilitam apreender a ausência de uma relação dialógica entre pais e profissionais, reforçando o lugar desses últimos como detentores do conhecimento acerca do que acontece com a criança. Embora o diálogo seja defendido na relação entre profissionais e familiares por se acreditar que é o que demarca a diferença entre um cuidado integral e um mero cumprimento de protocolos (23), os encontros dos profissionais com os pais funcionam como um espaço de transferência de informação. Uma estratégia para a construção de diálogos entre eles está na possibilidade de os pais entenderem o que está sendo falado pelo profissional, vincularem-se a ele e receberem notícias que reflitam a singularidade do recém-nascido (17). Nesse sentido, acreditamos que o estabelecimento de uma relação dialógica torna mais concreto o atendimento às necessidades do profissional e dos pais na passagem de notícias.

Ao expressar a aprendizagem possível nesse período de internação, os pais revelam a capacidade de, nas interações estabelecidas entre sujeitos e entre sujeitos e ambiente, recriar a si e as condições para viver nesse espaço. Em um movimento de autopoiese que emerge do experienciado e da disponibilidade para tal, são criados novos modos de agir e de existir.

Lidar com o óbito, além de, culturalmente, trazer a tristeza pela perda (24) pode representar, para os profissionais, o insucesso de seu trabalho, sem que necessariamente seja por assistência inadequada. A dificuldade em lidar com esse tipo de desfecho está também relacionada à impotência dos profissionais frente à morte e à sensação de fracasso por não terem sido capazes de cumprir seu papel de curar (25).

Evidencia-se, na análise dos dados, que, mesmo a mãe acreditando saber o que é melhor para a sua filha, o profissional desqualifica sua percepção e interpõe, em sua relação com a mãe, a autoridade de determinar os cuidados que considera adequados à criança. Esse achado configura-se em um forte obstáculo à construção de uma relação entre os profissionais e os pais que permita preparálos para os cuidados a seu filho. Faz-se necessário avançar no reconhecimento de que os pais, com suporte e orientação da equipe, podem desenvolver grande parte do cuidado com seus filhos (26).

Diferentes tecnologias são operadas pelos profissionais e pelos pais, ao cuidarem de seus filhos. No caso específico relatado por Orquídea (U-66, 68), evidencia-se que a profissional utilizou predominantemente as tecnologias contidas nos equipamentos e no saber sistematizado na produção do cuidado para o neonato, ao passo que a mãe se deixa guiar pelas tecnologias relacionais, na busca por atender às necessidades de sua filha.

Depreende-se, da situação relatada, que o desejo da mãe é ver sua filha na posição que lhe parece proporcionar maior conforto e o da profissional é cumprir a prescrição, a adequação do posicionamento à patologia ou a rotina de manuseio. Contudo, ao serem colocadas essas diferentes possibilidades de cuidado, não foi percebida como a possibilidade de valorização da observação materna, do entendimento e respeito mútuos, enfim a possibilidade de proposição de um cuidado que melhor atendesse aquela criança na sua singularidade. $\mathrm{O}$ que se evidencia é que a tecnologia dura e leve-dura utilizada pelo 
profissional impõe-se sobre a leve operada pela mãe e essa diversidade que poderia dinamizar as mudanças na produção de atos de saúde apresenta-se como um obstáculo ao acentuar ainda mais a distância entre o julgamento da mãe quanto ao melhor cuidado para seu filho e o julgamento e a ação do profissional.

Uma estratégia a ser considerada para se tornar mais sinérgico o trabalho da equipe e as possibilidades de participação da mãe seria a instituição de "praças de conversas" (27) as quais seriam espaços para profissionais e pessoas envolvidas no cuidado exporem seus projetos, e, nessa situação específica aqui discutida, o cuidado ser pactuado, sendo mãe e recém-nascido protagonistas dessa assistência.

Os pais buscam manter a segurança de seus filhos ao identificarem as circunstâncias que os colocam em risco ou a contradição entre o cuidado realizado e o que realmente seria melhor para o seus bebês. Verifica-se que as mães desenvolvem um conjunto de ações para proteger seus filhos, buscam transformar as situações que lhes conferem risco e apontam para a necessidade de os profissionais buscarem compreender o objetivo das ações maternas e tornarem-se parceiras para uma atenção qualificada (28).

Estamos adotando neste estudo como parceria a participação da mãe, não restrita à execução de cuidados com seu filho, mas sua participação nas definições do cuidado a ser realizado, com suporte da equipe para aumentar sua capacidade de oferecer mais cuidados a seu filho e oportunidade de discutir com a equipe o que tem observado nele (29).

A partir desse entendimento de parceria que vai ao encontro da atenção que tem como pressuposto a centralidade no recémnascido e sua família e, com base nos discursos dos participantes e na observação de campo, podemos inferir que, no cenário de estudo, ainda é incipiente a construção de parcerias com as famílias para o cuidado ao neonato. Assim, acreditamos ser necessário o reconhecimento, por parte da equipe que assiste o recém-nascido, das diferenças existentes, na perspectiva do olhar dos pais que, associadas ao fazer do profissional, podem favorecer a integralidade da assistência ao neonato e serem disparadoras de uma série de outras ações.

Os discursos são reveladores das mudanças proporcionadas pela constante presença da mãe no Hospital expressando necessidades de saúde e impondo novos arranjos assistenciais. Mesmo com as limitações à participação materna, traduzidas por comunicação falha entre equipe e família, acreditamos que a pura presença da mãe na instituição já implica em algum tipo de participação. Um dos desafios, portanto, é avançar na qualificação dessa participação e, tomando o contexto do cenário em estudo, isso deverá ser feito com a presença das mães.

Mesmo com o reconhecimento da importância da acolhida da família para o atendimento integral, o discurso dos profissionais revela uma participação restrita à presença física e uma família restrita à figura materna. É uma contradição que se revela na construção de novas práticas. É necessário que os profissionais superem a defesa de uma inserção presente apenas no discurso e desenvolvam ações e atitudes propositivas para a sua concretização.

No entendimento de cuidador principal como aquele que tem total ou maior responsabilidade pelos cuidados de determinada pessoa (30) defendemos que a mulher continue sendo a cuidadora principal de seu filho recém-nascido e que a equipe e familiares a reconheçam como tal, construindo com ela condições de se fortalecer nessa relação.

Os achados da presente pesquisa apontam para o imprescindível papel dos profissionais, especialmente os técnicos de enfermagem, para aumentar o sentimento de participação das mães no cuidado de seu filho. 


\section{CONSIDERAÇÕES FINAIS}

O discurso dos informantes é revelador do que vivenciam na UTIN, expressando as características desse espaço de atenção e como o cotidiano que compartilham os transformam, permitindo-lhes criar outros sentidos para a vida e para o cuidar. Em sua permanência na UTIN, os pais percebem a realidade/acontecimentos, apropriam-se dela e agem, estimulados pela conjuntura do espaço assistencial. Nessa vivência, os pais socializam sua subjetividade e compartilham o habitus que está em contínua construção.

Os discursos dos informantes são reveladores de como se estabelece a relação entre os pais e os profissionais na Unidade assistencial, evidenciando sentimentos que a permeiam e a estruturam e outros aspectos que interferem na relação estabelecida, tais como a duração da permanência da criança no hospital, a assistência prestada e o que é apreendido pelos pais em suas observações.

Mesmo com os limites das ações dos pais, verifica-se que sua presença ressignifica o ambiente assistencial e o cuidado oferecido e amplia as demandas de cuidado para a criança e a família. As modificações que essa presença produz no ambiente da UTIN impõem um constante repensar e replanejar do trabalho dos profissionais exigindo mais da equipe de saúde. Isso torna necessário que se proponham estratégias para que os profissionais também se sintam apoiados e consigam atender as demandas do recém-nascido e de sua família.

Acreditamos na necessidade de intervenções na Unidade assistencial, a partir do que é aí vivenciado por pais, profissionais e recémnascidos, utilizando-se os diferentes olhares para a produção de um cuidado integral ao recém-nascido e a sua família.

\section{REFERÊNCIAS}

1. Duarte ED, Sena RR, Xavier CC. Processo de trabalho na Unidade de Terapia Intensiva Neonatal: construção de uma atenção orientada pela integralidade. Rev Esc Enferm USP. 2009; 43(3):647-54.

2. Cleveland LM. Parenting in the Neonatal Intensive Care Unit. J Obstet Gynecol Neonatal Nurs. 2008; 37(6): 666-91.

3. Turan T, Babakal Z, Özbek S. Effect of nursing interventions on stressors of parents of premature infants in neonatal intensive care unit. J Clin Nurs. 2008; 17(21): 2856-66.

4. Broedsgaard A, Wagner L. How to facilitate parents and their premature infant for the transition home. Int Nurs Rev. 2005; 52(3):196-203.

5. Miles MS, Funk SG, Carlson J. Parental stressor scale: neonatal intensive care unit. Nurs Res. 1993; 42(3): 148-52.

6. Miles MS, Funk SG, Kasper MA. The stress response of mothers and fathers of preterm infants. Res Nurs Health.1992; 15(44): 261-69.

7. Carmona EV, Lopes MH. Content validation of parental role conflict in the neonatal intensive care unit. Int J Nurs Terminol Classif. 2006, 17: 3-9.

8. Browne JV, Talmi A. Family-based intervention to enhance infant-parent relationships in the neonatal intensive care unit. J Pediatr Psychol. 2005; 30(8): 66777.

9. Trombini E, Surcinelli P, Piccioni A, Alessandroni R, Faldella G. Environmental factors associated with stress in mothers of preterm newborns. Acta Paediatrica. 2008; (97): 894-98.

10. Leite MA, Vila VSC. Dificuldades vivenciadas pela equipe multiprofissional na unidade de terapia intensiva. Rev Lat Am Enfermagem. 2005; 13(2):145-50. 
11. Wigert H, Hellstrom AL, Berg M. Conditions for parents' participation in the care of their child in neonatal intensive care - a field study. BMC Pediatr. 2008, 8(3): 1-9.

12. Petersen M F, Cohen J, Parsons V. Family-centered care: do we practice what we preach? J Obstet Gynecol Neonatal Nurs. 2004; 33 (4): 421-27.

13. Minayo MCS. O desafio do conhecimento: pesquisa qualitativa em saúde. 10a ed. São Paulo (SP): Hucitec, 2007. 408 p.

14. Afonso MLM. (Org). Oficinas em dinâmica de grupo: um método de intervenção psicossocial. São Paulo: Casa do Psicólogo, 2006. $171 \mathrm{p}$.

15. Rocha D, Deusdará BA. Análise de Conteúdo e Análise do Discurso: aproximações e afastamentos na (re)construção de uma trajetória. Alea. 2005;7(2):305-22.

16. Buarque V, Lima MC, Scott RP, Vasconcelos MGL. O significado do grupo de apoio para a família de recém-nascidos de risco e equipe de profissionais na unidade neonatal. J Pediatr (Rio J.). 2006; 82(4): 295-301.

17. Braga PP. Cuidado, trabalho e diálogo: as interações na construção da integralidade do cuidado ao recém-nascido internado em UTI [dissertação de mestrado]. [Belo Horizonte (MG)]: Escola de Enfermagem da Universidade Federal de Minas Gerais; 2006. 104 p.

18. Bialoskurski MM, Cox CL, Wiggins RD. The relationship between maternal needs and priorities in a neonatal intensive care environment. J Adv Nurs. 2002; 37(1): 62-9.

19. Bruce B, Ritchie J. Nurses'practices and perceptions of family-centered care. J Pediatr Nurs. 1997; 12 (4): 214-22.

20. Arockiasamy V, Holsti L, Albersheim S. Fathers' experiences in the neonatal intensive care unit: a search for control. Pediatrics. 2008;121 (2): 215-22.

21. Shields-Poë D, Pinelli J. Variables associated with parental stress in neonatal inten- sive care units. Neonatal Netw. 1997; 16: 29-37.

22. Mok E, Leung SF. Nurses as providers of support for mothers of premature infants. J Clin Nurs. 2006; 15(6): 726-34.

23. Junqueira MFP, Lamego D, Morsch DS, Deslandes SF. Os desafios da humanização em uma UTI neonatal cirúrgica. En: Deslandes SF. (org.). Humanização dos cuidados em saúde: conceitos, dilemas e práticas. Rio de Janeiro: FIOCRUZ, 2006. p. 261-82.

24. Walsh F, McGoldrick M. Um tempo para chorar: a morte e o ciclo de vida familiar. In: Walsh F, McGoldrick M. Morte na família: sobrevivendo às perdas. Tradução Cláudia Oliveira Dornelles. Porto Alegre: ArtMed, 1998. p. 56-76.

25. Lamy ZC. Unidade neonatal: um espaço de conflito e negociações [tese de doutorado]. [Rio de Janeiro (RJ)]: Instituto Fernandes Figueira na FIOCRUZ; 2000. $161 \mathrm{p}$.

26. Nyqvist KH, Engvall, G. Parents as their infant's primary caregivers in a neonatal intensive care unit. J Pediatr Nurs. 2009; 24(2): 153-63.

27. Merhy EE. Público e privado: entre aparelhos, rodas e praças. In: Aciole GG. A saúde no Brasil: cartografias do público e do privado. São Paulo (SP): HUCITEC; Campinas (SP): Sindicato dos Médicos de Campinas e Região; 2006.

28. Hurst I. Vigilant watching over: mother's actions to safeguard their premature babies in the newborn intensive care nursery. J Perinat Neonatal Nurs. 2001; 15(3): 39-57.

29. Moore KAC, Coker K, Dubuisson AB, Swett B, Edwards WH. Implementing Potentially Better Practices for improving family-centered care in neonatal Intensive care units: successes and challenges. Pediatrics. 2003; 111 Suppl: 450-60.

30. Barer B, Johnson CL. A critique of caregiving literature. Gerontologist. 1990; 30(1): 45-9. 